\title{
Maximizing the Science and Resource Mapping Potential of Orbital VSWIR Spectral Measurements of Mars
}

Primary author:

Scott L. Murchie

(240) 228-6235

Johns Hopkins Applied Physics Laboratory

11100 Johns Hopkins Rd., MS 200-W230

Laurel, MD 20723

Co-authors

Raymond E. Arvidson

Janice L. Bishop

Wendy M. Calvin

John Carter

John Christian

Roger N. Clark

Colin M. Dundas

Bethany L. Ehlmann

Valerie K. Fox

Abigail A. Fraeman ${ }^{1}$

Timothy A. Goudge

Briony H. Horgan

Madison N. Hughes

Ellen K. Leask

Alfred S. McEwen

John F Mustard

Mario Parente

Kathryn E. Powell

Frank P. Seelos

Kimberly D. Seelos

Jesse D. Tarnas

Christina E. Viviano

James J. Wray

Washington University in Saint Louis, St. Louis, MO, U.S.A.

SETI Institute, Mountain View, CA, U.S.A.

University of Nevada, Reno, NV, U.S.A.

Institut d'Astrophysique Spatiale, Paris, France

Washington University in Saint Louis, St. Louis, MO, U.S.A.

Planetary Science Institute, Tucson, AZ, U.S.A.

U.S. Geological Survey, Flagstaff, AZ, U.S.A.

California Institute of Technology, Pasadena, CA, U.S.A.

University of Minnesota, Minneapolis, MN, U.S.A.

Jet Propulsion Laboratory, California Institute of Technology,

Pasadena, CA, U.S.A.

University of Texas, Austin, TX, U.S.A.

Purdue University, West Lafayette, IN, U.S.A.

Washington University in Saint Louis, St. Louis, MO, U.S.A.

Johns Hopkins Applied Physics Laboratory, Laurel, MD, U.S.A.

University of Arizona, Tucson, AZ, U.S.A.

Brown University, Providence, RI, USA

University of Massachusetts, Amherst, MA, U.S.A.

Northern Arizona University, Flagstaff, AZ, U.S.A.

Johns Hopkins Applied Physics Laboratory, Laurel, MD, U.S.A.

Johns Hopkins Applied Physics Laboratory, Laurel, MD, U.S.A. Brown University, Providence, RI, USA

Johns Hopkins Applied Physics Laboratory, Laurel, MD, U.S.A. Georgia Institute of Technology, Atlanta, GA, U.S.A.

${ }^{1}$ A portion of this work was carried out at the Jet Propulsion Laboratory, California Institute of Technology, under a contract with the National Aeronautics and Space Administration (80NM0018D0004).

Signatories: Elizabeth Rampe, NASA/Johnson Space Center, Houston, TX, U.S.A.; Alice Lucchitti, Maurizio Pajola, National Institute of Astrophysics (INAF), Padova, Italy; Andrew Annex, Johns Hopkins University, Baltimore, MD, U.S.A.; Jeffrey R. Johnson, Debra L. Buczkowski, Johns Hopkins Applied Physics Laboratory, Laurel, MD, U.S.A.; Laura Fackrell, University of Georgia, Athens, GA, U.S.A.; Samuel F. A. Cartwright, University of Nevada, Reno, NV, U.S.A.; Katelyn Frizzell, Rutgers, \The State University of New Jersey, New Brunswick, NJ, U.S.A. 


\section{A Word from the Authors}

We are a diverse group of researchers ranging in age from senior faculty to graduate students, who share a common experience of analysis and interpretation of Mars orbital visible/short-wave infrared (VSWIR) spectral data in the context of supporting robotic Mars rovers. Our common experiences provide insight into the future potential for orbital VSWIR techniques to advance understanding of the geology and resources of the Martian surface.

\section{Executive Summary}

The last 16 years witnessed a rapid growth in understanding the composition and aqueous alteration of Mars' surface from orbital data from the Observatoire pour la Mineralogie, l'Eau, les Glaces et 1'Activité (OMEGA) [1] and Compact Reconnaissance Imaging Spectrometer for Mars (CRISM) [2]. Both are sensitive to water-, hydroxyl-, sulfate-, and carbonate-bearing and ferric phases that record past liquid water. As the spatial resolution of such data has improved, and supporting laboratory data have been acquired, the diversity of mineral phases that are recognized has likewise expanded. The same phases typically contain recoverable water, a resource for future human exploration, and are the only near-surface water reservoir in the $>50 \%$ of Mars over which ice likely does not occur in the shallowest subsurface. Knowledge of the distribution and abundance of these water-bearing phases, and their geologic implications, is limited by spatial resolution of the available data. A revolutionary advance in understanding the inventory, diversity, and stratigraphy of these materials can be obtained from Mars orbit, using two complementary approaches: hyperspectral imaging at $\sim 6$ meters per pixel at 0.7-4 $\mathrm{m}$, and 1 meter-per-pixel imaging at selected VSWIR wavelengths from 0.4-1.7 $\mu \mathrm{m}$.

\section{Recent Results of VSWIR Orbital Mapping of Mars}

VSWIR wavelengths contain absorptions diagnostic of primary and secondary minerals present in Mars' crust. These absorptions are caused by electronic transitions due to $\mathrm{Fe}^{2+}$ in olivine, pyroxene, and glass and $\mathrm{Fe}^{3+}$ in oxides / oxyhydroxides as well as plagioclases that contain a trace of $\mathrm{Fe}^{2+}$ [3-7]. Absorptions are also caused by vibrations in $\mathrm{H}_{2} \mathrm{O}-, \mathrm{OH}_{-}, \mathrm{SO}_{4-}$, and $\mathrm{CO}_{3}$-bearing hydrated / hydroxylated silicates, sulfates, oxyhydroxides, and carbonates [8-13].

Detailed knowledge of mineral composition of Martian rock formations began with the Imaging Spectrometer for Mars (ISM) onboard the Phobos 2 spacecraft [14]. Its improved spatial resolution compared to Earth-based telescopic measurements revealed heterogeneity in the strength of the $3-\mu \mathrm{m}$ absorption associated with molecular $\mathrm{H}_{2} \mathrm{O}$.

The first global compositional maps from Mars orbit used thermal infrared (TIR) wavelengths measured by the Thermal Emission Spectrometer on Mars Global Surveyor (TES, $\sim 6 \mathrm{~km} /$ pixel [15]) and the Thermal Emission Imaging System on Mars Odyssey (THEMIS, 100 $\mathrm{m} / \mathrm{pixel}[16]$ ). These found an overall basaltic composition of highlands crust, regional differences in primary mineral abundances, olivine-rich units, and a distinct composition of the northern plains [17-20]. Relatively few aqueously formed minerals were recognized initiallyhematite in Meridiani Planum and elsewhere [21] and chlorides in the highlands [22].

OMEGA on Mars Express (0.3-1 km/pixel) and CRISM on Mars Reconnaissance Orbiter (18 or $36 \mathrm{~m} / \mathrm{pixel}$ ) confirmed those inferred primary rock compositions and, additionally, revealed heterogeneity in pyroxene composition in the southern highlands [23] and abundant glass as the cause of the distinct composition of the northern plains [24]. They also revealed a large variety of secondary minerals that had not been apparent in TIR data. At OMEGA's spatial resolution, hydrated sulfates in association with the hematite discovered by TES, plus a variety of clay minerals, are apparent over large areas [25-27]. At CRISM's 15-50x higher spatial 
resolution a far greater variety of minerals has been discerned, and their geologic settings characterized with the aid of $\sim 0.3 \mathrm{~m} /$ pixel images from HiRISE [28]. Among the key phases are hydrated silica indicating extensive leaching [29], serpentine and prehnite indicating hydrothermal alteration of the crust at elevated temperature [30,31], carbonate minerals indicating formation in liquid water at a neutral to alkaline $\mathrm{pH}$ [32], and a variety of other minerals having more limited occurrence that bound the range of temperatures and pressures at which low-grade metamorphism of the highlands crust occurred [33-35]. Poorly crystalline aluminosilicates (e.g., allophane) indicate environments where liquid water was transient [36].

In aggregate, CRISM and OMEGA data - combined with constraints on stratigraphy from HiRISE - indicate nearly a dozen distinct aqueous environments including lightly altered subsurface bedrock, three variants of clastic- or evaporite-dominated lake sediments, pedogenic horizons, eolian sediments cemented by acid sulfates from saline groundwater discharge, acidleached silica-rich materials, and hot springs [33,34,37]. Several of these environments have been studied in situ by rovers, and CRISM characterizations have been critical for establishing geologic context beyond rover traverses, generating testable hypotheses, and highlighting specific outcrops for investigation. For example, Wray et al. [38] identified metal-OH and $\mathrm{H}_{2} \mathrm{O}$ absorptions indicative of clay-bearing material on the rim of Endeavour crater. In situ observations by the Opportunity rover substantiated this inference, and demonstrated the majority of the clays formed post-impact by fluids that circulated through fractures, with limited volumes of rock indicating more extensive leaching [39,40]. Milliken et al. [41] inferred from CRISM data and HiRISE images that the lower beds of Mount Sharp in Gale crater were claybearing sediments, and in situ analyses by Curiosity's instrument suite substantiated the clay detections and demonstrated that they formed in a habitable lacustrine environment [42-43].

Arranged temporally based on stratigraphy and crater densities, these distinct environments trace the climatic evolution of early Mars (Fig. 1; [44]). Aqueous alteration from the preNoachian through the late Noachian periods was dominated by formation of phyllosilicates and, rarely, carbonates, which indicate a generally neutral to alkaline $\mathrm{pH}$ environment. Significant alteration occurred in the subsurface at low to moderate temperatures (from $<0{ }^{\circ} \mathrm{C}$ in brine, locally or regionally to $200-400^{\circ} \mathrm{C}$ as sub-greenschist facies metamorphism). Deposition of secondary minerals in surface water and pedogenic formation of smectites were concentrated during a relatively short interval that occurred during the mid- to late Noachian period when relatively warm, wet conditions prevailed [45-47], and less so during the early Hesperian period in lacustrine environments including at Gale crater $[42,48]$. Younger deposits having aqueously formed minerals, emplaced mostly before the mid-Hesperian period, are hematite-, sulfate-, or silica-rich materials that formed in a drying, acidic environment.

\section{Convergence of Science and Resource Mapping}

Indicator minerals of past aqueous environments typically contain "bound water," coordinated to sulfate or carbonate molecules or trapped in crystal structures of hydrated silicates. As such, many aqueous mineral assemblages that record past wet environments also provide an "ore" of water, oxygen, and hydrogen for future human explorers [49], particularly at latitudes $\leq 35^{\circ}$ at which shallow near-surface ice has not been detected [50]. Based on a synthesis of orbital estimates and ground truth measurements of water abundance, it is possible to estimate the water recoverable from various formations [49]. Typical soils may yield $\sim 1 \mathrm{wt} . \% \mathrm{H}_{2} \mathrm{O}$ by heating to $\sim 400{ }^{\circ} \mathrm{C}$. Some formations enriched in aqueous minerals may have $2-10 \mathrm{wt}$ \% bound $\mathrm{H}_{2} \mathrm{O}$ in sulfate, carbonate, or clay, recoverable (depending on the phase) by heating to $100-$ $250^{\circ} \mathrm{C}$. Such resources are being mapped globally using CRISM and OMEGA data [51,52]. 


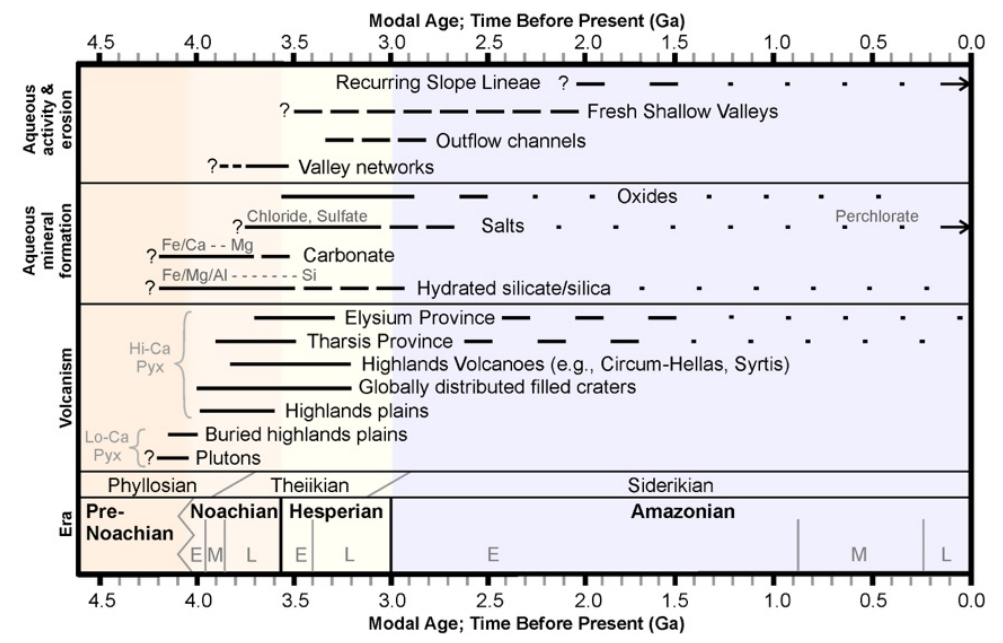

Figure 1. Schematic history of Martian alteration environments as indicated by secondary mineralogy, compared with time stratigraphic periods and the ages of water-related surface features and geologic units rich in alteration morphologies. Modified from Murchie et al. (2020).

\section{The Challenge: Spatial Resolution}

As summarized in MEPAG's NEX-SAG report [53], improving the spatial resolution of orbital VSWIR spectroscopy by a factor of 3- to $\sim 6 \mathrm{~m} /$ pixel-would enhance interpretation of the history and resource potential of rock formations that include aqueously formed minerals, enabling characterization of the Martian surface far beyond current capabilities.

Evolution of the knowledge of Martian surface composition using VSWIR spectroscopy illustrates this important point: as resolution has improved from the regional to outcrop scale, more of the diversity of Martian surface composition is detectable. For example, hydrated silicarich deposits near Valles Marineris were unresolved by OMEGA, but easily resolved by CRISM. Evidence is clear that improved spatial resolution-to 1 meter per pixel-would continue to yield new discoveries. CRISM has employed an observing technique whereby some observations are spatially oversampled. Ground processing enables rendering of the data at an improved resolution with a pixel scale of 12 or even $9 \mathrm{~m} /$ pixel vs. the $18 \mathrm{~m} /$ pixel native spatial sampling [54]. Studies that use this approach demonstrate detection of small exposures that are not resolvable at $18 \mathrm{~m} /$ pixel, yielding a more detailed view of compositional stratigraphy that has in turn driven rover traverse planning [40,55-57]. Comparison of CRISM and Curiosity measurements reveals what limits orbital detectability of bedrock spectral variations: dust cover and muting of spectral absorptions by multiple materials, such as dark basaltic sand, occurring within a single pixel [58]. These limitations can be addressed through improved resolution of dust- and debris-free windows, which would guide rovers to the most interesting locations.

Of critical importance, volumetric estimates of aqueous mineral deposits for in situ resource utilization requires high resolution mapping of their thickness through vertical windows (scarps, crater walls) which is not currently practical at CRISM's spatial resolution.

In addition, new techniques to process CRISM data have emerged that should inform design of future orbital investigations. The "Fandango" group serves as a forum to compare them [59].

Key among them is spatially oversampling a scene and rendering it with resolution improved by $\mathbf{2 5 0 \%}$ [54], leveraging data volume to simulate an instrument with greater focal length (and mass and cost). Also, noise in the data can be reduced using any of several methods; one highly effective approach that has been employed uses a Maximum Log-likelihood Method with weighting penalties to denoise and reconstruct the data [60]. The denoised data are of sufficient quality to highlight small spectral differences that can be correlated with surface topography to separate spectral variations due to bedrock heterogeneity versus mass wasting and debris cover, a critical capability to fully utilize improved spatial resolution [61]. Finally, 
CRISM-measured thermal emission at 3.4-4 $\mu \mathrm{m}$ has been used to estimate thermal inertia at 18 $\mathrm{m} /$ pixel, a $>5 \mathrm{x}$ improvement over THEMIS, revealing texture at the same scale as composition, to provide additional information with which to interpret lithology of near-surface materials [62].

\section{Key Questions for Future Orbital Investigation}

The MEPAG NEX-SAG report [53] identified high priority questions to be investigated by a future orbital VSWIR investigation: (1) What are the nature and relative prevalence of different parent lithologies in the Noachian crust that interacted with liquid water, and how were they affected by metamorphism? (2) What were the relative prevalence of different environmental settings involving liquid water: surface water bodies, transient surface water, near-surface weathering, and diagenesis, hydrothermalism, serpentinization, and metamorphism at depth? (3) What controls the observed spatial variability in secondary mineralogy? (4) What are the relative roles of endogenic heating and impact heating in driving alteration? (5) What is the full inventory of mineral water resources in the shallow subsurface? Each of these questions can be addressed through VSWIR observations with improved spatial resolutions compared to CRISM.

MEPAG Goals 2020 [63] identified high priority investigations in Goal III, Origin and Evolution of Mars as a Geological System, that closely parallel the questions articulated in the NEX-SAG report and are directly addressed by compositional mapping at improved spatial resolution: Investigation A1.1-Determine the modern extent and volume of liquid water and hydrous minerals within the crust; Investigation A1.2-Identify the geologic evidence for the location, volume, and timing of ancient water reservoirs; Investigation A2.1-Constrain the location, volume, timing, and duration of past hydrologic cycles that contributed to the sedimentary and geomorphic record; Investigation A2.2-Constrain the location, composition and timing of diagenesis of sedimentary deposits and other types of subsurface alteration; Investigation A2.3-Identify the intervals of the sedimentary record conducive to habitability and biosignature preservation; Investigation A3.1-Link geologic evidence for local environmental transitions to global-scale planetary evolution; and Investigation A3.2-Determine the relative and absolute age, durations, and intermittency of ancient environmental transitions.

\section{Recommended Investigations Using the Modern State of the Art}

During the Mars Orbiter for Resources, Ices and Environments (MORIE) Planetary Mission Concept Study [64], different techniques for future VSWIR orbital investigations were explored. Two (whose attributes are shown in Figs. 2 and 3) emerged as complementary and feasible:

\subsection{High-Resolution Imaging Spectroscopy}

One concept is a follow-on hyperspectral imager to CRISM, having a wavelength range of at least $0.7-4 \mu \mathrm{m}$ to cover absorptions due to key secondary minerals as well as thermal emission from the surface. Coverage of shorter wavelengths to $\leq 0.5 \mu \mathrm{m}$ would provide improved discrimination of ferric and other phases. Spatial sampling of $\sim 6 \mathrm{~m} /$ pixel would improve resolution of compositional stratigraphy (Fig. 3). This approach requires, compared to CRISM, an instrument with a longer focal length and larger aperture, plus gimbaling to support oversampling to allow rendering of the data at even better spatial resolution.

\subsection{High-resolution Multispectral Imaging at an Expanded Wavelength Range}

A complementary concept is meter-per-pixel multispectral imaging at selected VSWIR wavelengths that captures spectral heterogeneity due to key absorptions. New, large-format $\mathrm{HgCdTe}$ arrays allow a cross-track scene width at least that of HiRISE and can accommodate $\sim 20$ fixed strip filters. Selected bands (Fig. 2) include widely spaced 60- and 30-nm bands with a 
few 10 -nm bands around narrow $\mathrm{H}_{2} \mathrm{O} / \mathrm{OH} / \mathrm{CO}_{2}$ absorptions. Preliminary calculations indicate that signal to noise ratio $>100$ (sufficient for detecting spectral features identified by CRISM at many sites across Mars) can be attained in the 60- and 30-nm bands (and in 10-nm bands with $2 \times 2$ pixel binning) using time-domain integration over 64 pixels with a $20-\mathrm{cm}$ aperture imager.
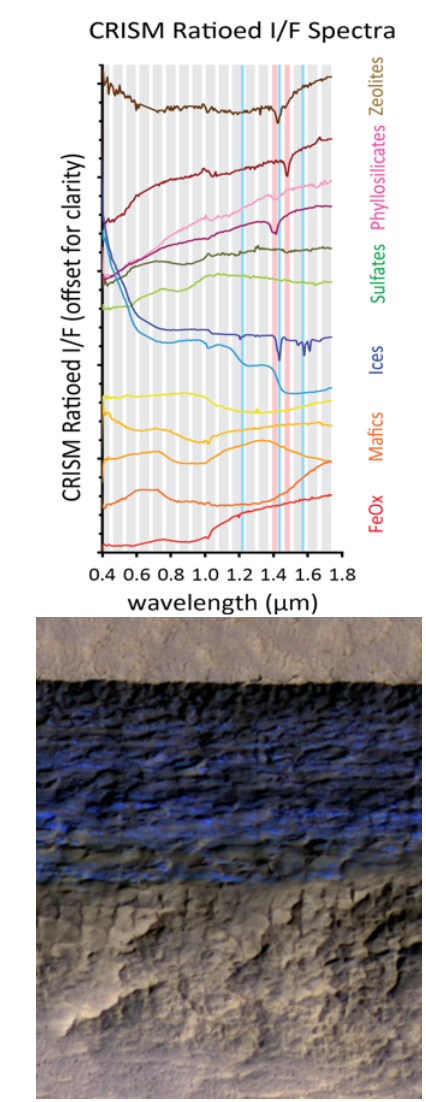

HiRISE $0.26 \mathrm{~m} / \mathrm{pixel}$

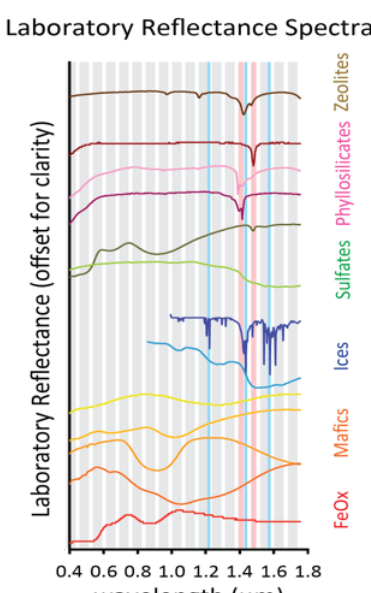
wavelength $(\mu \mathrm{m})$

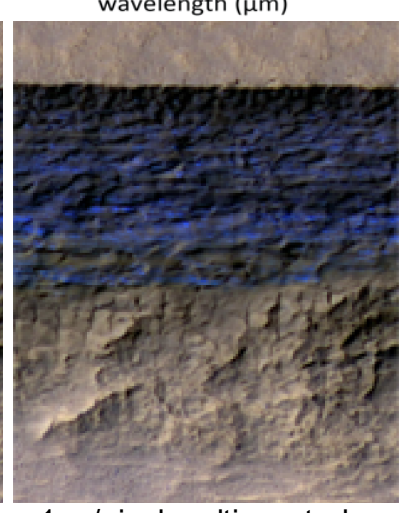

$1 \mathrm{~m} /$ pixel multispectral

Figure 2 (left). Schematic illustration of 60$\mathrm{nm}$ (gray), 30-nm (pink) and 10-nm (light blue) bandpasses in a passively cooled, 0.4$1.7 \mu \mathrm{m}, 20-\mathrm{cm}$ aperture $1 \mathrm{~m} /$ pixel VSWIR multispectral imager, that could be used to map occurrences of minerals which have been detected in MRO/CRISM images at resolution approaching that of HiRISE color.

Figure 3 (below). HiRISE image ESP_021466_1230 showing 120-m thick icerich deposit rendered at different resolutions.

\section{References}

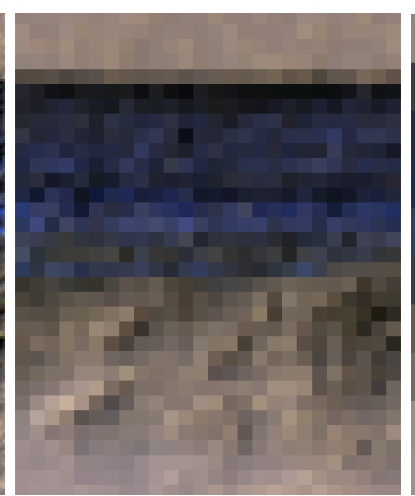

$6 \mathrm{~m} /$ pixel hyperspectral

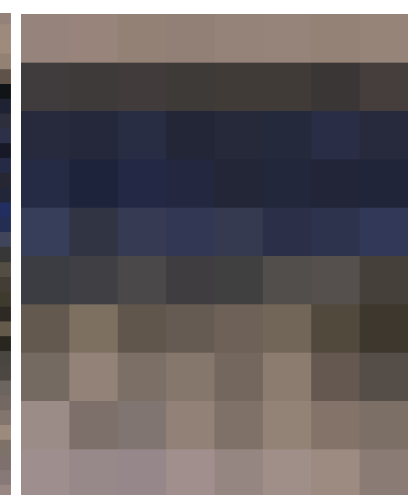

CRISM $18 \mathrm{~m} / \mathrm{pixel}$

[1] Bibring J.-P. et al. (2004) OMEGA: Observatoire pour la Minéralogie, l'Eau, les Glaces et l'Activité. In: Mars Express: The scientific payload (A. Wilson, ed.). ESA SP-1240. ESA Publications Division, Noordwijk, Netherlands, 37-49. [2] Murchie S et al. (2007) Compact Reconnaissance Imaging Spectrometer for Mars (CRISM) on Mars Reconnaissance Orbiter (MRO). J. Geophys. Res, 112, E05S03. [3] Adams J. (1974) Visible and near-infrared diffuse reflectance spectra of pyroxenes as applied to remote sensing of solid objects in the solar system. J. Geophys. Res., 79, 4829-4836. [4] Cloutis E. \& Gaffey M. (1991) Pyroxene spectroscopy revisited: Spectral-compositional correlations and relationship to geothermometry. J. Geophys. Res., 96, 22,809-22,826. [5] Sherman D., Burns R. \& Burns V. (1982) Spectral characteristics of the iron oxides with application to the Martian bright region mineralogy. J. Geophys. Res., 87, 10,169-10,180. [6] Sunshine J., Pieters C. \& Pratt S. (1990) Deconvolution of mineral absorption bands: An improved approach. J. Geophys. Res., 95. 6955-6966. [7] Rossman G.R. \& Ehlmann B.L. (2020) Electronic spectra of minerals in the visible and near-infrared. In Remote Compositional Analysis, ed. by J. Bishop et al., Cambridge Univ., 3-20. [8] Hunt G.R. \& Salisbury J.W. (1971a) Visible and near infrared spectra of minerals and rocks. II. Carbonates. Mod. Geol., 2, 23-30. [9] Hunt, G. \& Salisbury J. (1971b) Visible and infrared spectra of minerals and rocks. IV: Sulphides and sulphates. Mod. Geol., 3, 1. [10] Rossman, G.R. (1976) Spectroscopic and magnetic studies of ferric iron hydroxysulfates: The series $\mathrm{Fe}(\mathrm{OH}) \mathrm{SO}_{4} \cdot n \mathrm{H}_{2} \mathrm{O}$ 
and jarosite. Am. Mineralogist, 61, 398-401. [11] Clark R.N. et al. (1990) High spectral resolution reflectance spectroscopy of minerals. J. Geophys. Res., 95, 12,653-12,680. [12] Cloutis E.A. et al. (2006) Detection and discrimination of sulfate minerals using reflectance spectroscopy. Icarus, 184, 121-157. [13] Bishop J.L. (2020) Chapter 4: Visible and nearinfrared reflectance spectroscopy of geologic materials. In Remote Compositional Analysis, ed. by J. Bishop et al., Cambridge Univ., 68-101. [14] Bibring J.-P. et al. (1989) Results from the ISM experiment. Nature, 341, 591-593 [15] Christensen P.R. et al. (2001) Mars Global Surveyor Thermal Emission Spectrometer experiment: Investigation description and surface science results. J. Geophys. Res., 106, 23,823-23,871. [16] Christensen P.R. et al. (2004) The Thermal Emission Imaging System (THEMIS) for the Mars 2001 Odyssey mission. Space Sci. Rev., 110, 85- 130. [17] Bandfield J.L. et al. (2000) A global view of Martian surface compositions from MGS-TES. Science, 287, 1626-1630. [18] Hamilton V.E. \& Christensen P.R. (2005) Evidence for extensive, olivine-rich bedrock on Mars. Geology, 33, 433-436. [19] Rogers A.D. \& Christensen P.R. (2007) Surface mineralogy of martian low-albedo regions from MGS TES data: implications for crustal evolution and surface alteration. J. Geophys. Res., 112, E01003. [20] Hamilton V.E. et al. (2020) Thermal infrared spectral analyses of Mars from orbit using the Thermal Emission Spectrometer and Thermal Emission Imaging System. In Remote Compositional Analysis, ed. by J. Bishop et al., Cambridge Univ., 484-498. [21] Christensen P.R. et al. (2000) Detection of crystalline hematite mineralization by the Thermal Emission Spectrometer: evidence for near-surface water. J. Geophys. Res., 105, 9623-9642. [22] Osterloo M.M. et al. (2008) Chloride-bearing materials in the southern highlands of Mars. Science, 319, 1651-1654. [23] Mustard J.F. et al. (2005) Olivine and pyroxene diversity in the crust of Mars. Science, 307, 1594-1597. [24] Horgan B.H. \& Bell J.F. III (2012) Widespread weathered glass on the surface of Mars. Geology, 40, 391-394. [25] Poulet F. et al. (2005) Phyllosilicates on Mars and implications for early martian climate. Nature, 438, 623-627. [26] Arvidson R.E. et al. (2005) Spectral reflectance and morphologic correlations in eastern Terra Meridiani, Mars. Science, 307, 1591-1594. [27] Gendrin A. et al. (2005) Sulfates in martian layered terrains: The OMEGA/Mars Express view. Science, 307, 1587-1591. [28] McEwen, A. S. et al. (2007) Mars Reconnaissance Orbiter's High Resolution Imaging Science Experiment (HiRISE). J. Geophys. Res., 112, E05S02. [29] Milliken R.E. et al. (2008) Opaline silica in young deposits on Mars. Geology, 36, 847-850. [30] Ehlmann B.L. et al. (2009) Identification of hydrated silicate minerals on Mars using MRO-CRISM: Geologic context near Nili Fossae and implications for aqueous alteration. J. Geophys. Res., 114, E00D08. [31] Ehlmann B.L. et al. (2010) Geologic setting of serpentine deposits on Mars. Geophys. Res. Lett., 37, 6-10. [32] Ehlmann B.L. et al. (2008) Orbital identification of carbonate-bearing rocks on Mars. Science, 322, 1828-1832. [33] Carter J. et al. (2013) Hydrous minerals on Mars as seen by the CRISM and OMEGA imaging spectrometers: Updated global view. J. Geophys. Res., 118, 831-858. [34] Ehlmann B.L. \& Edwards C.S. (2014) Mineralogy of the Martian surface. Ann. Rev. Earth Planet. Sci., 42, 291315. [35] Murchie S.L. et al. (2020) VSWIR spectral analyses of Mars using CRISM \& OMEGA. In Remote Compositional Analysis, ed. by J. Bishop et al., Cambridge Univ., 453-483. [36] Bishop J.L. \& Rampe E.B. (2016) Evidence for a changing Martian climate from the mineralogy at Mawrth Vallis. Earth and Planetary Sci. Lett., 448, 42-48. [37] Murchie S.L. et al. (2009) A synthesis of Martian aqueous mineralogy after one Mars year of observations from the Mars Reconnaissance Orbiter. J. Geophys. Res., 114, E00D06. [38] Wray J.J. et al. (2009) Diverse aqueous environments on ancient Mars revealed in the southern highlands. Geology, 37, 1043-1046. [39] Arvidson R.E. et al. (2014) Ancient aqueous environments at Endeavour crater, 
Mars. Science, 343, 1248097. [40] Fox V.K. et al. (2016) Smectite deposits in Marathon Valley, Endeavour crater, Mars, identified using CRISM hyperspectral reflectance data. Geophys. Res. Lett., 43, 4885-4892. [41] Milliken R.E., Grotzinger J.P. \& Thomson B.J. (2010) Paleoclimate of Mars as captured by the stratigraphic record in Gale crater. Geophys. Res. Lett., 37, L04201. [42] Grotzinger J.P. et al., (2014) A habitable fluvio-lacustrine environment at Yellowknife Bay, Gale crater, Mars. Science, 343, 1242777. [43] Rampe E.B. et al. (2020) Mineralogy and geochemistry of sedimentary rocks and eolian sediments in Gale crater, Mars: A review after six Earth years of exploration with Curiosity, Geochemistry, 80, 125605. [44] Bibring, J.-P,.et al. (2006) Global mineralogical and aqueous Mars history derived from OMEGA/Mars Express data. Science, 312, 400-404. [45] Ehlmann B.L. et al. (2011) Subsurface water and clay mineral formation during the early history of Mars. Nature, 479, 53-60. [46] Carter J. et al. (2015) Widespread surface weathering on early Mars: A case for a warmer and wetter climate. Icarus, 248, 373-382. [47] Bishop J.L. et al. (2018) Surface clay formation during short-term warmer and wetter conditions on a largely cold ancient Mars. Nature Astronomy, 2, 206-213. [48] Grotzinger J.P. et al., (2015) Deposition, exhumation, and paleoclimate of an ancient lake deposit, Gale crater, Mars. Science, 350, 6257, aac7575. [49] Murchie S.L. et al. (2016) Geological water resources for humans on Mars: Constraints from orbital spectral mapping and in situ measurements. Lunar Planet. Sci. 47, abstract \#1261. [50] Piqueux S. et al. (2019) Widespread shallow water ice on Mars at high and mid latitudes. American Geophysical Union, Fall Meeting 2019, abstract \#P54A-07. [51] Seelos F.P. et al. (2019) CRISM next generation Mars global multispectral map-Hydrated mineralogy spectral parameter mapping. Lunar Planet. Sci. 50, abstract \#2635. [52] Riu L. et al. (2019) Global distribution of abundances of hydrated minerals on Mars and derived water content. Lunar Planet. Sci. 50, abstract \#1177. [53] MEPAG (2015) Report from the Next Orbiter Science Analysis Group (NEX-SAG) http://mepag.nasa.gov/reports.cfm. [54] Kreisch C.D. et al. (2016) Regularization of Mars Reconnaissance Orbiter CRISM along-track oversampled hyperspectral imaging observations of Mars. Icarus, 282, 136-151. [55] Fraeman A.A. et al. (2013) A hematite-bearing layer in Gale crater, Mars: Mapping and implications for past aqueous conditions. Geology, 41, 1103-1106. [56] Arvidson R.E. et al. (2015) Mars Reconnaissance Orbiter and Opportunity observations of the Burns formation: Crater hopping at Meridiani Planum. J. Geophys. Res., 120, 2014JE004686. [57] Powell, K et al. (2017) The structural, stratigraphic, and paleoenvironmental record exposed on the rim and walls of Iazu crater, Mars. J. Geophys. Res. Planets, 122, 1138-1156. [58] Fraeman A.A. et al. (2019) Synergistic orbital and in situ observations at Vera Rubin Ridge: Comparing CRISM and Curiosity observations. Lunar Planet. Sci. 50, abstract \#2118. [59] Parente M. et al. (2019) Convergence on mineral detections over Gale Crater, NE Syrtis, and Jezero crater using advanced data processing techniques for CRISM hyperspectral imaging data. Lunar Planet. Sci. 50, abstract \#3112. [60] He, L. et al. (2019) Quantitative reconstruction and denoising method HyBER for hyperspectral image data and its application to CRISM. IEEE Journal of Selected Topics in Applied Earth Observations and Remote Sensing. [61] Hughes M.N. et al. (2020) Mass movements and debris deposits in the Grand Canyon and Gediz Vallis, Gale crater, Mars. Lunar Planet. Sci. 51, abstract \#2426. [62] Christian J. R. et al. (2020) CRISM-derived thermophysical properties of Gale crater, Mars. Lunar Planet. Sci. 51, abstract \#1317. [63] MEPAG (2020) Mars Scientific Goals, Objectives, Investigations, and Priorities: 2020, https://mepag.jpl.nasa.gov/reports.cfm. [64] Calvin W. et al. (2020) Mars Orbiter for Resources, Ices and Environments (MORIE) Planetary Mission Concept Study. 